\title{
Das Preußische
}

\section{Verfassungsrecht}

Auf der Grundlage der Verfassung des Freistaats Preußen systematisch dargestellt

von

\section{Dr. Fritz Stier-Somlo,} ordentlicher Professor des öffentlichen Rechts und der Politik an der Universität Köln

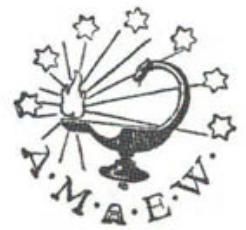

B o $\mathrm{n} \mathrm{n} 1922$

A. Marcus und E. Webers Verlag (Dr. jur. Albert Ahn) 


\section{Nachdruch verboten.}

Alle Rechte,

besonders das der Übersetzung in fremde Sprachen, behält sich der Verlag vor. Copyright 1922 by A. Warcus \& E. Webers Verlag, Bonn. 
Meinem lieben Kollegen

\section{Herrn Dr. Heinrich Lehmann}

ord. Professor der Rechte und Rektor der Universitāt Köln,

dem glänzenden Rechtslehrer und modernen Forscher

freundschaftlichst zugeeignet. 



\section{Vorwort.}

Hiermit übergebe ich die meines Wissens erste wissenschaftliche systematisehe Darstellung des preuBischen Verfassungsrechts der Öffentlichkeit. Sie ist, wie mein 1919 (und in 2. Auf?. 1920) in demselben Verlage erschienener, Systematischer Überblickder Verfassung des Deutschen Reichs vom 11. A ugust", ein Versuch. Beide Schriften ergänzen sich riicht nur durch das Ineinandergreifen von Reichs- und Landesstaatsrecht, sondern auch durch die geschichtliche, nur in dem früheren Werke einläßlich behandelte Entwicklung der verfassungsrechtlichen Dinge im Reich und Preußen seit der Revolution im November 1918, die Behandlung des Problems des Unitarismus und Föderalismus, die meist nur in einer meiner beiden Schriften zu findende Nachweisung und Verwertung desjenigen Schrifttums, das Reichs- wie Landesstaatsrecht angeht.

Die preußische Verfassungsurkunde habe ich in einem cingehenden Kommentar (Berlin, Vereinigung Wissenschaftlicher Verleger, 1921) behandelt. Es ergibt sich aus ler vorliegenden Schrift, worin sich hinsichtlich Stoffauswahl, Methode und äuBerer Form das hier Gebotene von dem Kommentar unterscheidet. Beanten- und Ämterrecht ist, ursprünglicher Absicht entgegen, nach reiflicher Überlegung, als dem Verwaltung s recht angehörig, nicht behandelt worden. Immerhin ist in diesem jüngeren svstematischen Überblick ein noch reicheres und bis auf den heutigen Tag vervollständigtes Material verarbeitet und, bei leicht begreiflicher Übereinstimmung meiner hier vorgetragenen Ansichten mit denen im Kommentar, manches, wie ich glaube, besser gestaltet worden; auch sind einzelne frïhere Irrtümer berichtigt, auf abweichende Meinungen stets Rücksicht genommen, die Literatur erschöpfend beriicksichtigt worden.

Universität Köln, den 15. August 1921. 